\title{
Leiomyosarcoma: a rare complication of uterine fibroid
}

\author{
Shazia Parveen*, Noor Afshan Sabzposh, Amina Kuraishy \\ Department of Obstetrics \& Gynaecology, JN Medical College \& Hospital, AMU, Aligarh, UP, India
}

Received: 15 April 2014

Accepted: 4 May 2014

\section{*Correspondence:}

Dr. Shazia Parveen,

E-mail: shzparveen@gmail.com

(C) 2014 Parveen S et al. This is an open-access article distributed under the terms of the Creative Commons Attribution Non-Commercial License, which permits unrestricted non-commercial use, distribution, and reproduction in any medium, provided the original work is properly cited.

\begin{abstract}
Uterine sarcomas are rare tumours of mesodermal origin. Malignant change occurring in uterine fibroid is termed as leiomyosarcoma. They constitute around 2-6 \% uterine malignancies and $25-36 \%$ of uterine sarcomas ${ }^{1}$. The tumour is common in women between the age group 40-50 years. It has an aggressive course \& usually metastasis goes to the lungs. The prognosis for women with uterine sarcoma primarily depends on the extent of disease at the time of diagnosis and mitotic index ${ }^{3}$. Women with tumor size $>5 \mathrm{~cm}$ in maximum diameter have poor prognosis. These tumours should be diagnosed and managed with no delay and must be followed vigilantly as the rate of recurrence $\&$ metastasis is very high.
\end{abstract}

Keywords: Fibroid, Leiomyosarcoma, Mesodermal tumour

\section{INTRODUCTION}

Uterine sarcomas are rare tumours of mesodermal origin. Malignant change occurring in uterine fibroid is termed as leiomyosarcoma. They constitute around 2-6 \% uterine malignancies and $25-36 \%$ of uterine sarcomas. ${ }^{1}$ The tumour is common in women between the age group 4050 years. It has an aggressive course \& usually metastasis goes to the lungs.

\section{CASE REPORT}

A 50 years post-menopausal female presented to us in our OPD at JNMCH, AMU, Aligarh with the complaints of post-menopausal bleeding per vaginum off and on for 5 months and foul smelling discharge per vaginum for 15 days. She was $\mathrm{P}_{6}+\mathrm{O}$ menopausal for past 8 years $\&$ was a known case of hypertension.

On examination she was pale and her vitals were stable. Her abdominal examination revealed a palpable mass of 16 week size in the supra pubic region which on per vaginum examination mass was confirmed having a soft consistency.
On per speculum examination she had foul smelling discharge. She was admitted to the ward and started with broad spectrum antibiotics. Her lab investigations revealed anemia $\mathrm{Hb}-10 \mathrm{~g} \%$, deranged RFT (BU - 84 $\mathrm{mg} \%$, SC $-2.3 \mathrm{mg} \%$ ). USG revealed hypoechoic lesion in the anterior wall of the uterus size $(74 \mathrm{~cm} \times 53 \mathrm{~cm} \times 53$ $\mathrm{cm}) \mathrm{B} / \mathrm{L}$ ovaries were normal and endometrial thickness was not made out. MRI showed enlarged uterus with altered signal intensity lesion filling the endometrial cavity and cervical canal of size $12.2 \mathrm{~cm} \mathrm{x} 8.2 \mathrm{~cm}$ x 8.7 $\mathrm{cm}$ without parametrial involvement with bilateral inguinal lymph node enlargement of size $(2 \mathrm{~cm} \times 1.26$ $\mathrm{cm})$. Uterine aspiration was done \& HPE revealed uterine leiomyosarcoma. $\mathrm{X}$ ray chest was done it was normal.

The lump progressed in size \& achieved a 20 week size and on per speculum examination tongue shaped mass was coming through cervical Os.

Total abdominal hysterectomy with $\mathrm{B} / \mathrm{L}$ salpingooophorectomy was done bowel was explored it was normal. Specimen was sent for HPE which revealed stromal sarcomatous change with leiomyomatous differentiation. 
In the post-operative period patient received combination chemotherapy (Vincristine, adriamycin and cyclophosphamide) \& discharged from the ward in satisfactory general condition.

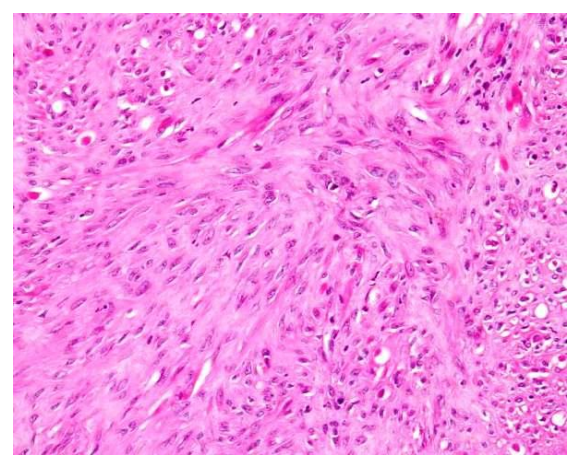

Figure 1: Histopathology report: shows spindle cells typical of uterine leiomyosarcoma

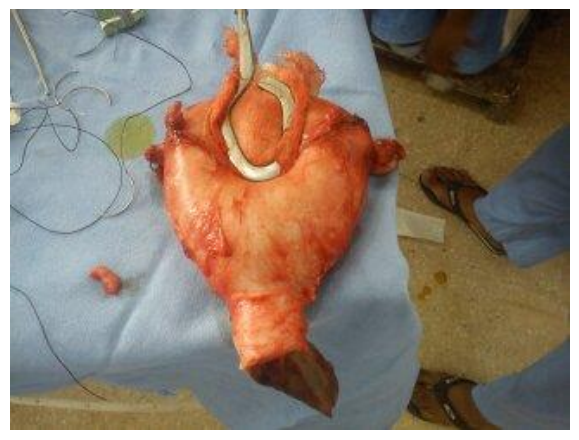

Figure 2: Polypoidal brown mass seen coming out from cervix involving whole of the uterus.

\section{DISCUSSION}

The etiology of ULMS is unknown but pre-disposing factors may include (40-60 years of age), AfricanAmerican race $\&$ obesity it is not related to parity. ${ }^{2}$

The 3 most common histologic variants of uterine sarcomas are Endometrial Stromal Sarcoma (EES), leiomyosarcoma and carcinosarcoma (malignant mixed Mullerian tumors).

The incidence of sarcomatous change in benign uterine leiomyomas is reported between $0.13 \%$ and $0.18 \%$.

Incidence of mixed mullerian sarcoma is $50 \%$, leiomyosarcoma is $30 \%$, endometrial stromal carcinoma is $15 \%$ and adenosarcoma is $5 \%$.

Symptoms are of usually short duration (mean 6 months) include vaginal bleeding, pelvic pain, or pressure and abdominopelvic mass. ${ }^{2}$ The diagnosis of uterine sarcoma is made from histological examinations of entire uterus. Leiomyosarcoma tumors may be spindle shaped cell. On macroscopic appearance the outer surface is haemorrhagic, irregular \& soft. Metastasis is by - blood stream - to lungs and kidneys. Through lymphatics - to pelvic LN in stage I \& II (35\% paraotic LN 15\%). By direct speed - metastasis in peritoneum and omentum.

Mitotic count more than 10/HPF and atypical cell is warning sign. Treatment of stage I \& II uterine sarcoma should include total abdominal hysterectomy with bilateral salpingo-oophorectomy \& treatment of pelvic lymphatics by radiation/surgery. Strong consideration should be given to the use of adjunct chemotherapy to decrease the incidence of distant metastasis. Commonly used chemotherapeutic agents are vincristine, adriamycin (doxorubicin) and cyclophosphamide. Though surgical resection is beneficial for improving patient outcome, the 5 year survival rate for patient with stage I ULMS is $53 \%$ $\& 8 \%$ for stage II-IV.

\section{CONCLUSION}

The prognosis for women with uterine sarcoma primarily depends on the extent of disease at the time of diagnosis and mitotic index. ${ }^{3}$ Women with tumor size $>5 \mathrm{~cm}$ in maximum diameter have poor prognosis. These tumours should be diagnosed and managed with no delay and must be followed vigilantly as the rate of recurrence \& metastasis is very high.

\section{Funding: No funding sources \\ Conflict of interest: None declared \\ Ethical approval: Not required}

\section{REFERENCES}

1. Jitendra K. Patel, Kelley L Cervellione, Muhammad Sulh, Avani A. Patel, Jonas Gintautas. A rare case of uterine leiomyosarcoma metastasis to the duodenum. Proc West Phamacol Soc. 2009;52:8-10.

2. Giuntoli, RL 2nd, Metzinger DS, Di Marco CS, Keeney GL. Retrospective review of 208 patients with leiomyosarcoma of the uterus: prognostic indicators, surgical management, and adjuvant therapy. Gynaecol Oncol. 2003;89:460-9.

3. Major FJ, Blessing JA, Silverberg SG, Morrow CP, Creasman WT, Currie JL, Yordan F, Brady MF. Prognostic factors in early stage uterine sarcoma: a gynaecologic oncology group study. Cancer. 1993;71(40):1702-9.

DOI: $10.5455 / 2320-1770 . i j r \operatorname{cog} 20140646$

Cite this article as: Parveen S, Sabzposh NA,

Kuraishy A. Leiomyosarcoma: a rare complication of uterine fibroid. Int J Reprod Contracept Obstet Gynecol 2014;3:486-7. 